\title{
La ironía de ser indígena y la imaginación del tiempo social ${ }^{1}$
}

\section{The irony of being indigenous and the imagination of social time}

\author{
Ángel DÍAZ DE RADA \\ Universidad Nacional de Educación a Distancia (UNED) \\ Departamento de Antropología Social y Cultural \\ adiaz@fsof.uned.es
}

Recibido: 2 de julio de 2014

Aceptado: 9 de noviembre de 2014

\section{Resumen}

Este ensayo trata de un viejo asunto: la reflexión sobre la noción "indígena" en el contexto de sus usos temporales. La referencia clásica es la obra de Johannes Fabian Time and the Other (1983), y el campo de aplicación, en este caso, los usos de la palabra "indígena" en algunas formas de identificación de nuestros contemporáneos en el norte de Escandinavia. La tesis básica de este ensayo es que la noción "indígena" se inserta habitualmente en un juego de ironías, debido a su orientación de-temporalizada en relación con los agentes en los actos de enunciación. A la luz de esta problemática, este ensayo critica las persistentes fórmulas de exotización de la antropología contemporánea, y subraya de nuevo la radical contemporaneidad de aquéllos cuyas prácticas representamos en nuestros discursos analíticos. Se distingue así la sensibilidad hacia la alteridad de la preferencia por el exotismo, y se retoma la idea de

${ }^{1}$ Una primera versión de este texto fue presentada en el Curso de Verano de la UNED Pueblos indigenas. Imágenes e imaginarios, coordinado por los profesores Fernando Monge y Alfredo Francesch. Parte de los materiales empíricos de este ensayo proceden del trabajo de campo realizado durante once meses en los inviernos de 2002, 2003 y 2004, en el Ártico Europeo. Durante esos períodos viví en la localidad de Guovdageaidnu (Kautokeino, Noruega). El proyecto de referencia de esta investigación llevaba por título "The Construction of Belonging. Expressive Practices and Appropriations of Identity among 'Saamis' and 'Norwegians' in Kautokeino." En el año 2000, el Departamento de Exteriores del Gobierno Noruego (Utenriksdepartementet) me becó para aprender la lengua Sami en la Universidad de Tromsø. En 2002, recibí una ayuda de la Wenner-Gren Foundation for Anthropological Research (Gr. 6898), que fue complementada con otra concedida por el Vicerrectorado de Investigación de la UNED. Para el invierno de 2003-2004, recibí una nueva ayuda Wenner-Gren (Gr. 7092), que fue complementada gracias al Programa de Movilidad del Profesorado del Ministerio de Educación, Cultura y Deporte (PR2003-0276). Muchas de las actuales elaboraciones sobre este proyecto se han visto reforzadas en proyectos posteriores, especialmente el último titulado "Madrid cosmópolis. Prácticas emergentes y procesos metropolitanos" (Ministerio de Economía y Competitividad, CSO2012-33949), desarrollado en el contexto del Grupo de Cultura Urbana de la UNED. Deseo agradecer sus comentarios a los profesores David Teira y Montserrat Cañedo, que se unieron a los de los dos lectores anónimos de la $R A S$ para la mejora de la versión final. 
una etnografía irónica (Brown 1999) como un esfuerzo agonístico y colaborativo de dotar de inteligibilidad al mundo contemporáneo.

Palabras clave: "indígena”; ironía; alteridad y exotismo; intersubjetividad; sápmi.

\begin{abstract}
This essay deals with an old issue: The elaboration of the notion 'indigenous' in the context of its temporal uses. The classic reference is Johannes Fabian's book Time and the Other (1983), and the field of application is, in this case, the uses of the word 'indigenous' in some forms of identification among our contemporaries in North Scandinavia. The basic argument in this essay is that the notion 'indigenous' is usually embedded in a play of ironies, due to its detemporalized orientation to the agents in the enunciation acts. In dealing with this problem, this essay criticizes the persistent formulas of exotization in contemporary anthropology, and underlines again the radical coevalness with those people whose practices we represent in our analytic discourses. A distinction is proposed between sensibility towards alterity and preference for exotism, and Brown's idea of an ironic ethnography (Brown 1999) is taken as an agonistic and collaborative effort to give some intelligibility to our contemporary world.
\end{abstract}

Keywords: "indigenous"; irony; alterity and exotism; intersubjectivity; sápmi.

Referencia normalizada: Díaz de Rada, Á. (2015) La ironía de ser indígena y la imaginación del tiempo social, en Revista de Antropología Social 24, 433-449.

SUMARIO: 1. Tópicos. 2. Ironía. 3. Agente alterizado. 4. "Indígenas" y "Samis". 5. Contemporaneidad. 6. Intersubjetividad agonística. 7. Referencias bibliográficas.

It takes imagination and courage to picture what would happen to the West (and to anthropology) if its temporal fortress were suddenly invaded by the Time of its Other (Fabian, 1983:35).

\title{
1. Tópicos
}

La palabra indígena apunta, en su génesis, a una toma de distancia de quien la enuncia. En latín, inde-gens: "gente de allí"; aunque si consideramos el adverbio inde en toda su extensión evocaríamos también una distancia temporal: "desde entonces".

Como indicó Johannes Fabian (1983), la antropología creó su objeto sobre la base de complejas traducciones de la distancia espacial en distancia temporal. La palabra "indígena", en sus múltiples usos, condensa esos ejercicios de traducción, que son juegos con el tiempo social; es decir, juegos con las relaciones sociales entendidas como relaciones entre tiempos. De forma introductoria, solamente ilustraré tres de esos juegos, fácilmente identificables entre muchos otros, que son ya tópicos de nuestra disciplina. El primer juego, heredero de las narrativas bíblicas, consiste en predicar del "indígena" su existencia en un tiempo originario, un estado literal "de naturaleza". Amerigo Vespucci lo expresó en 1502: "no tienen ley ni fe ninguna, 
viven de acuerdo a la naturaleza, no conocen la inmortalidad del alma" (Vespucci, 1502: 76). El segundo juego, que coincide con el anterior en la predicación orientalista de una negatividad del otro (Baumann y Gingrich, 2004), consiste en atribuir al "indio" un tiempo congelado, que preparó la retórica del presente etnográfico. $\mathrm{He}$ aquí un ejemplo extraído del tratado de Tomás López Medel De los tres elementos, fechado en torno a 1570 :

En lo que toca a la condición y particular suerte de aquella nación, es el indio humilde, de bajos pensamientos, sin punta de ambición y soberbia, simple, sencillo, no nada entrincado ni malicioso; de poco consejo, poco advertido, de poca Providencia en lo por venir, de manera que in praesentem diem vivit [vive en el presente] sin cuidado de lo de mañana; flaco, fácil, frágil y poco constante (López Medel, $c a$. 1570: 208).

El tercer juego consiste, en contraste, en una predicación igualmente orientalista de la negatividad del nosotros. López Medel continúa así el texto anterior, sentando precedente para la alegoría etnográfica (Clifford, 1986):

\begin{abstract}
Vea ahora y juzgue la locura y demasía nuestra y de todo el mundo de por acá. ¿Quién, con demasiados trabajos, demasiados amores y con más licenciosos artificios y perniciosos modos de vivir se ha apartado y alejado más de aquella hoja de higuera de nuestro primero padre y de aquella pobreza antigua y del cumplimiento de aquella rigurosa sentencia que contra él se dio: in sudore vultus tui vesceris pane tuo [ganarás tu pan con el sudor de tu frente] [...]? (López Medel, Ibid.: 209).
\end{abstract}

Como indicó Berta Ares en el Estudio Preliminar de su edición del libro de López Medel, esa imagen del "indio" impugnaba utópicamente el presente cambiante y "licencioso" del nosotros (Ares, 1990: LIX). Y lo hacía — cabría añadir- anudando el pasado mítico con el futuro salvífico, en un presente que, en su condición de inmutable, situó al "indio" fuera del tiempo, es decir, de la experiencia social del tiempo. Esos tres juegos con el tiempo social concurren en la imagen creada por Johannes Fabian: el "indígena", excluido así de la experiencia ordinaria del tiempo comunicativo, es un objeto alócrono para aquél que lo toma en consideración.

Todos esos perfiles concurren en las interpretaciones habituales de las palabras para designar "indígena" en Sami, de las que cabe sospechar una formación relativamente reciente y trasladada desde las pragmáticas y semánticas de las lenguas de los colonizadores: álgoálbmot ("pueblo originario"); y, con una mayor complejidad, eamiálbmot, donde el atributo eami- forma un espacio de interpretación próximo a "primitivo", "congénito", "innato", "connato", "de nacimiento", "connatural" (Kåven et al., 1995: 158, y de aquí Blom-Dahl, 1991: 178).

\title{
2. Ironía
}

En el tiempo de la comunicación concreta, la enunciación de la palabra "indígena" como forma de identificación de quien habla como un yo, y de aquél a quien se habla como un tú, impide la literalidad, en la medida en que transporte las interpretaciones contenidas en esos tópicos; pues es literalmente imposible que 
esas personas, en ese acto comunicativo, se encuentren fuera de su presente social compartido (cf. Fabian, 1983: 82-85).

En Guovdageaidnu es difícil encontrar una ocasión para entrevistar a los pastores trashumantes de $\operatorname{renos}^{2}$. Ello se debe a las exigencias de dedicación que les impone su trabajo en la tundra. Fijar una cita de reloj en el núcleo urbano es, con ellos, una tarea complicada. En febrero de 2004, aprovechando un encuentro con una amiga que conocía muy bien las rutinas de los pastores, le pedí consejo sobre cuándo podría ser un buen momento para intentar fijar una entrevista que llevaba tiempo persiguiendo. Ella me sugirió que lo intentase después de la luna llena de febrero, cuando — según me dijo - las tareas en el reno se relajan durante unas semanas. Oírla hablar en lunas me sonó realmente "indígena". El foco fundamental de mi trabajo se centraba más bien en procesos políticos de rabiosa actualidad, así que me encontraba muy lejos de verme ilusionado por lo que, en ese momento, consideré con escepticismo como una idealización tradicionalista. Antes de que yo llegase a formular la ironía que tenía en la punta de la lengua, mi amiga, directiva de una relevante institución escolar, cogió de la mesa la misma agenda en la que acabábamos de anotar nuestra próxima cita y, al ver las referencias que en ella aparecían al calendario lunar, comentó con naturalidad: "tienes que darte prisa, porque la próxima luna llena es dentro de poco días". En décimas de segundo cambió mi interpretación de la situación. Esa agenda que nosotros acabábamos de usar también hablaba en lunas. Entonces entendí que no debía ironizar sobre el consejo de mi amiga y empecé a considerar que no se trataba de "indios que siguen a la luna", sino de "trabajadores que cumplen con su agenda", como yo mismo lo hacía. No eran ya "indígenas" de otro tiempo, sino "personas" que habitaban en mi rabiosa actualidad.

A menudo, los usos cotidianos de la noción "indígena" están fundados sobre la ironía. No trato aquí de la ironía en términos meramente lingüísticos. En mi diario de campo hay muchos ejemplos de ironías verbales producidas por las personas en sus retóricas de identificación étnica, etnopolítica e indigenista. No me ocupo aquí del estudio de esas ironías en términos de una teoría de la mención (Sperber y Wilson, 1981; Wilson y Sperber, 1992); y, aunque mi enfoque es deudor del tratamiento más potente y complejo que ofrece Robert Martin sobre los conceptos de mundos contrafactuales y mundos de expectativas, no pongo el énfasis, como él hace con maestría, en menudos ejemplos de verbalización (Martin, 1992). Aquí me ocupo de reflexionar sobre una experiencia humana que emerge de una imagen contrafactual en relación con el tiempo de la comunicación ordinaria: la imagen que, cuando se trata de juegos de identificación en concretos contextos comunicativos, opera desarticulando la sincronía entre el yo (o el tú) y el objeto de identificación. Esa imagen se asienta en lo que Fernandez y Taylor, tomando una idea de Kenneth Burke, denominan “auténtica Ironía [True irony]”; la que, a diferencia de la sátira, el

${ }^{2}$ Un contexto de mi trabajo de campo en esta localidad del norte de Noruega y su entorno puede obtenerse, por ejemplo, en Díaz de Rada (2008a, 2008b). Los elementos empíricos se muestran aquí con la única intención de ilustrar el argumento reflexivo de fondo, y ello conlleva inevitablemente una limitación de su contexto de producción y de su riqueza etnográfica. 
sarcasmo o la parodia, "no pretende poseer un sentido de cómo funciona el mundo, de las causas y de las soluciones" (Fernandez y Taylor, 2001: 22). La auténtica ironía "habita en la incertidumbre, con una especie de sentido cósmico de la finitud y la mutabilidad de todo lo humano" (Ibíd.)

La ironía es una forma expresiva extendida en la comunicación humana y nada la asocia específicamente a la tematización "indígena" o a sus entornos de significado. Por otra parte, la experiencia de la mutabilidad que, bajo el identificador "indígena", han vivido las personas en contextos históricos de vinculación, subordinación, dominación, marcación, afirmación, y resignificación étnica (cf. Brown, 1999), entre otras posibilidades, es fuente de múltiples formas de expresión incoativa (Fernandez, 2006), y por tanto tropológica o figurativa. Sin embargo, la ironía en ese sentido que formuló Kenneth Burke ocupa una posición central en la pragmática cotidiana de la expresión "indígena", quizás debido a su condición menos figurativa ${ }^{3}$ y más deíctica: la ironía no expresa tanto un desplazamiento entre significados, es decir, en sentido estricto, un tropo, cuanto indica la condición ontológicamente incierta de los universos de creencias (cf. Martin, 1992), y de los mundos vitales de los agentes de la comunicación.

\section{Agente alterizado}

El contexto de interpretación de la noción "indígena" opera generalmente, cuando se trata de una autoidentificación, tomando al sí mismo como un otro. La alterización del sí mismo es un hecho ordinario (Ricoeur, 1990); pero en los usos de la palabra "indígena" se encuentra intensificada debido a su inevitable referencia a un tiempo otro, un tiempo pasado marcado por una condición originaria.

Esa alterización del sí mismo hunde además sus raíces en la historia colonial; y, en la práctica, se hace inteligible cuando pensamos en las formas específicas de la socialización en situaciones coloniales. En esas situaciones, las personas subordinadas en la relación de dominación han venido formado competencias culturales que, al ser consideradas como recursos agenciales (cf. Kockelman, 2007), son ambivalentes. En el mejor de los casos, esos recursos han ampliado el horizonte agencial del colonizado; pero, simultáneamente, han facilitado la capacidad de dominación del colonizador. Así puede entenderse en este pasaje del diario del primer viaje de Cristóbal Colón, tal como fue interpretado por Bartolomé de las Casas. Ahí leemos que, cuando navegaban en busca de la isla de Babeque por la costa cercana al Río del Sol, a Colón

[...] le había parecido que fuera bien tomar algunas personas de las de aquel río para llevar a los Reyes, porque aprendieran nuestra lengua para saber lo que hay en la tierra, y porque volviendo sean lenguas de los cristianos y tomen nuestras costumbres y las cosas de la Fé [...] (Fernández de Navarrete, 1999:48).

${ }^{3}$ La condición figurativa o tropológica de la ironía verbal ha sido objeto de debate particular. Veáse Kerbrat-Orecchioni (1980, sobre todo el apartado "II. La spécificité du trope ironique", 118 y ss.). Para una crítica introductoria de la visión tropológica de la ironía en la "retórica clásica", véase Wilson y Sperber (1992: 54 y ss). 
Ese agente alterizado es fuente habitual de ironía verbal, cuando, al relatar su propia historia biográfica, toma por objeto las formas específicas de acción que fue encastrando en su vida, a lo largo del proceso de transformación cultural (Díaz de Rada, 2010). No se trata ya aquí de materiales empíricos fácilmente etiquetables bajo la categoría de dominación colonial o etnopolítica; sino de un proceso mucho más sutil y penetrante en la vida cotidiana, una educación sentimental en formas de acción que, incorporadas en el repertorio del agente, son vividas bajo la sombra de un incierta experiencia de extrañamiento de lo propio (o de apropiación de lo ajeno).

Marie Anne me dio dos buenos ejemplos en noviembre de 2003, cuando hablé con ella sobre las transformaciones de las que fue testigo a lo largo del último tercio del siglo XX en Guovdageaidnu. En su infancia, como parte de su programa de "ayuda" social, la Iglesia Pentecostal les traía "ropas noruegas" (dáččabiktasat ${ }^{4}$.

Yo con esas ropas me moría de frío - dijo Marie Anne. Nunca había pasado tanto frío con las ropas samis. Pero, aunque las ropas samis eran muy buenas, nuestras madres tenían que trabajar mucho para hacerlas; especialmente cuando había muchos niños, era mucho trabajo. Así que - acabó reconociendo Marie Anne con una $\underline{\text { sonrisa - tal vez para mi madre era bueno recibir ese regalo de los Pentecostalistas }}{ }^{5}$.

Sin solución de continuidad, Marie Anne pasó a ironizar sobre la comida, para la cual no fue necesario ningún empujón caritativo. Como refuerzo a la condición alterizada del discurso, quiero llamar la atención sobre el vertiginoso juego de la pronominalización y la impersonalización en el siguiente pasaje:

Así empezamos a utilizar aquellas ropas noruegas; y también la comida... aunque esto dependió de nosotros mismos, dependió de la gente. - Marie Anne rioCuando fueron sintiendo cómo comían otras personas, qué clase de comida comían, desearon probarlo, y así empezó a comerse comida extraña y a comprarla; tenías que ir a la tienda a comprar lo que fuera. Y cuando oímos que con el pan debía usarse pålegget $t^{6} \ldots$ era algo malo si no se ponía pålegget, había que poner algo sobre el pan; - riendo de nuevo- debía hacerse así. Era un poco como negativo cuando no ponías nada sobre el pan, ¿no? —-Maria Anne concluyó con una risa más-Sí... algo como de pobre, de pobreza.

Un día estaba yo comiendo con Lasse en la cafetería de la Escuela Sami de Estudios Superiores (Sámi Allaskuvla). Ambos habíamos cogido del autoservicio unos panes con pålegget de jamón y pepinillos. Poco después llegó Anders con el mismo

${ }^{4}$ La palabra dáčca , que he traducido aquí como noruego, hace referencia a la persona y atributos considerados "noruegos" que no son considerados "samis".

${ }^{5}$ Puesto que a algunos lectores les ha costado reconocer la ironía en algunos de estos textos de las personas del campo, subrayo el contenido que estoy interpretando de ese modo. He de llamar la atención sobre el hecho de que la interpretación de una ironía verbal es muy sensible al contexto comunicativo. Además, muy habitualmente esa interpretación no deriva del contexto meramente verbal, sino que exige marcadores o acotaciones de tono, gestuales o actitudinales.

${ }^{6}$ A legge på designa en Noruego la acción poner sobre. Este verbo se ha sustantivado en pålegget, que designa especialmente el trozo de vianda que se pone sobre una tajada de pan. 
plato. Los tres reímos cuando Lasse, tras mirar lo que había en el plato de su amigo, exclamó: " $N a$, don leat nu dáruiduvvon!" [ihay que ver cómo te has norueguizado!]

Con una historia política diferente — pues en $\mathrm{Sápmi}^{7}$, como en las Américas o en Australia, no podemos hablar en sentido estricto de descolonización-, estos ejemplos podrían añadirse a la interpretación de Taylor sobre la "zona de contacto" misional en Papúa Nueva Guinea (Taylor, 2001), glosada por Fernandez y Taylor de este modo en la introducción de su volumen Irony in Action. Anthropology, Practice, and the Moral Imagination:

[Taylor muestra] que el poder sutil de la ironía puede radicar, precisamente, en su ambigüedad con respecto a la auténtica posición del hablante, al marcar una ambivalencia acerca del sí mismo que es un rasgo clave de la condición postcolonial (Fernandez y Taylor, 2001:28).

El juego con los tiempos que configuró en su génesis colonial el imaginario de la noción "indígena", o más bien "indio", como entonces se decía generalmente; es también, en la versión vindicativa, indigenista y etnopolítica de los "pueblos indígenas", un irónico juego de lugares sociales. El "indio" de los colonizadores - $-\mathrm{y}$, si creemos a Fabian (1983), el "nativo" a cuya costa se fundó el objeto de la antropología- es un ser del que se pretende que, estando ahí y ahora, está en otro tiempo. El agente indigenista que se identifica con aquél, el agente que hoy dice de sí mismo "soy indígena" y, eventualmente, representa a los "indígenas", añade a esa paradoja temporal la condición existencial de una conciencia parcialmente distanciada de su mundo social inmediato. La participación de las personas con vocación etnopolítica e indigenista en instituciones de orientación universalista, y muy particularmente su formación académica, es fundamental en la conformación de esa toma de perspectiva o de distancia. Esa circunstancia es muy visible en Sápmi.

Hablé con Rita de sus experiencias personales de identificación en múltiples planos. Rita se encontraba matriculada en la Allaskuvla. Le sugerí que me expresase sus sentimientos sobre el ser "indígena", aclárandole que me interesaban las situaciones concretas de su vida en las que esos sentimientos pudieran haberse formado. Aunque más adelante amplió su discurso hacia imágenes más emocionales, basadas en todo caso en un distanciamiento reflexivo, su primera referencia fue una asignatura que había cursado recientemente en la Allaskuvla, en la que, entre otras cosas, había tenido la oportunidad de conocer aspectos del contexto jurídico internacional sobre los "pueblos indígenas".

\section{4. "Indígenas" y "Samis"}

El primer presidente del Foro Permanente de las Naciones Unidas sobre Asuntos Indígenas, cuya primera sesión se celebró en mayo de 2002, fue Ole Henrik Magga. Magga fue también primer presidente del Parlamento Sami de Noruega, instituido en 1989. En el plano internacional y en el plano de las políticas públicas del Estado

${ }^{7}$ Sápmi designa, en singular, a la persona identificada como "sami”, y, mucho más frecuentemente, a los territorios del Norte de Escandinavia marcados con tal atribución étnica. 
Noruego, la asociación entre "samis" e "indígenas" es hoy incuestionable. No fue siempre así. Según el relato del historiador Henry Minde, diversos prejuicios relacionados fundamentalmente con la integración de la "sociedad sami" en ese modelo de "primer mundo" que es el Estado Noruego, convirtieron el reconocimiento de los "samis" como "indígenas" en tema de debate en la primera sesión preparatoria del Consejo Mundial de los Pueblos Indígenas, celebrada en Guyana en 1974 (Minde, 1995:20 ss.)

Sin embargo, por aquel entonces no hacía tanto tiempo que se tenía por cierta la imagen de una población atrasada en relación con los estándares de desarrollo de Noruega. En 1959, se publicó la Propuesta para analizar la cuestión sami (Kirke- og Undervisningsdepartementet, 1959), encargada por el Estado Noruego a una comisión delegada. En su anexo 7, la propuesta incluía un informe elaborado por el médico Øyvind Jonassen sobre las Condiciones sociales e higiénicas en las zonas de campamento de los samis trashumantes (Jonassen, 1959). Basándose en su inspección sobre el terreno, Jonassen dio forma, con la retórica del "desarrollo", al imaginario alócrono sobre los "samis", su ubicación en un tiempo fuera del presente. Ese texto es un paradigma del discurso de distanciamiento temporal de los "samis" en relación con los "noruegos", más llamativo aún si se piensa que toda su lógica está inspirada en un horizonte de explícita inclusión con fórmulas como "nuestra población de trabajadores del reno" [vår reindriftsbefolkning (Jonassen, 1959:87)].

Las condiciones de vida de quienes viven aislados en el interior de la tundra se separan en un alto grado de las que son habituales hoy en nuestro país. No existe de hecho ningún grupo de población que se encuentre en una situación social, cultural y económica más desventajosa - cuando se valora en relación con las normas que son habituales en nuestro tiempo. Podemos afirmar también que, en muchos aspectos, viven en una situación peor que sus antepasados de varias generaciones atrás (Jonassen, 1959: 83, las cursivas son mías). El encuentro entre la cultura sami originaria y nuestro moderno nivel de vida no siempre ha tendido a resultar en una síntesis afortunada (Jonassen, 1959: 83).

En el siglo XXI, las condiciones referidas en ese texto de 1959 constituyen, en gran medida, un relato de la memoria. De manera que quienes se identifican como "samis", conscientes de ese pasado (que a su vez ya era un pasado, aparentemente, para el presente del "noruego" Øyvind Jonassen), y conscientes de que ser "indígena" encuentra su motivo fundamental en ser de un tiempo que no es éste del presente, orientan su identificación indigenista igualmente por medio de operaciones de distancia temporal. Si en 1959 un "noruego" operaba de ese modo temporalmente distanciado en relación con los "samis", en 2004 la joven Rita, que en un momento previo de la entrevista se había reconocido como "sami de adopción", se distanciaba social y temporalmente de los "indios" para poder expresar su identificación con ellos:

Ha sido así, desde muy al principio de mi infancia, $[\ldots]$ recuerdo que era niña y que veía a los indios [en libros, en la televisión] y escuchaba esa historia... tanto llanto... ¡Era tan doloroso! [...] Y yo pensaba que ojalá yo fuera india - riendo levemente¡en ello había una estimación tan alta! 


\section{Contemporaneidad}

Al criticar analíticamente la condición alócrona del sujeto construido por la antropología como objeto (el nativo, el primitivo, o - en el contexto de esta reflexión - el indígena), Johannes Fabian insistió en una idea: en todo caso, se ha tratado de negar su contemporaneidad (coevalness) (Fabian, 1983). Se ha tratado de negar, en definitiva, que esas personas viven en el mismo tiempo, al mismo tiempo que "nosotros". La ironía de ser indígena se basa en el modelo cultural de la alocronía, en la incertidumbre que conlleva pretender ser, en este tiempo, de otro tiempo. Por ello, en el plano subjetivo, es prácticamente imposible estar seguro de que se es "indígena". "Indígena" es una categoría crítica porque induce a moverse, inciertamente, entre tiempos: tiempos biográficos, tiempos míticos, pero también tiempos históricos y sociopolíticos. Quienes la usan luchan por la definición legítima del tiempo social en el que su experiencia (y su memoria) ha de cobrar sentido.

Por eso, nada más habitual que las sospechas que la palabra "indígena" despierta entre los propios "indígenas", es decir, entre quienes, con mayor o menor frecuencia, se identifican como tales. Y, cuando ya no se trata de hablar de uno mismo, sino de hablar de la gran política, ¿qué tiempo histórico es el tiempo del "indígena"? ¿dónde situar la escala temporal relevante para su definición como sujeto jurídico? ¿qué poder es legítimo para dictaminar quiénes son, dónde y cuándo existen los "indígenas"? Si sufrieron, y aún hoy sufren el desposeimiento de sus voluntades políticas bajo el pretexto arbitrario de su "estado de naturaleza", la alienación gratuita de sus territorios y recursos vitales bajo las variantes de la fórmula terra nullius, y la enajenación de su tiempo social bajo su categorización como poblaciones aborígenes, ¿en qué tiempo comenzar a datar su legitimidad como agentes políticos de su propia existencia, y, sobre todo, quién ha de hacerlo?

En Sápmi y en otros lugares, las luchas del indigenismo buscan construir un nuevo orden de legitimidad en relación con los estados nacionales. Quienes las ponen en práctica como representantes políticos o como agentes de asociaciones civiles, o quienes a título individual les dan expresión en su vida cotidiana, sólo pueden aspirar a ser escuchados, y, eventualmente, a ver reconocidos sus derechos, en el contexto de esa relación con el estado nacional. En ese contexto, los agentes están obligados a la literalidad, y en ello consiste una de las paradojas específicas de sus prácticas políticas y de sus expresiones públicas. En ese contexto de relación, y en las situaciones sociales que lo constituyen, esas personas han de jugar habitualmente en el campo de la burocracia estatal, y han de hacerlo con las herramientas categoriales plenamente reificadas, y normalmente esencialistas, de la burocracia estatal. Los que operan en ese campo de juego no están para ironías burkianas; crean o no crean en sus propias construcciones literales han de usarlas, y si no creen en ellas, han de aprender a distanciarse, cuando menos situacionalmente, de aquello en lo que creen. La negociación entre incertidumbre y certeza, entre flexibilidad y categorización esencialista forma parte de su acción práctica, y ello ha de ser así, si es que se busca que esa acción sea eficaz. No importa cuán inciertas sean sus autoidentificaciones, esas personas han de operar en el campo de certezas que fueron impuestas hace siglos en los procesos estatales de colonización, y que se han venido 
reproduciendo de formas crecientemente sutiles a lo largo de los siglos. Esas personas luchan por el reconocimiento de derechos bien concretos. Al hacerlo en Sápmi (NOU, 1984), deben sostener proyectos políticos inequívocamente formulados, y referidos a un sujeto político claramente designado desde el 17 de mayo de 1988 en la Consitución del Reino de Noruega: "el grupo de población Sami” [den samiske Folkegruppe] (Lovdata.no, 1814-2014: §110a). En sus debates con el Estado Noruego, esos agentes etnopolíticos han de saber quiénes son, y han de saber lo que buscan; esgrimen sus derechos históricos y lo hacen negociando sus certezas con las certezas de quienes gobiernan el Estado. Quienes argumentan con esas certezas pueden llegar a expresarse a través de la parodia o el sarcasmo, entre otras posibilidades retóricas, pues tienen una verdad que negociar con la verdad del Estado Nacional; pero no pueden hacerse cargo de los riesgos que entrañaría la expresión de incertidumbre que es propia de la ironía burkiana. Junto con esas certezas, en un orden de práctica diferente, se encuentran las expresiones de incertidumbre que intento caracterizar aquí. En éstas, la nítida categorización étnica o etnopolítica cede terreno a un delicado universo de categorías flexibles (Kramvig, 1999, 2005); y la certeza sobre el ser "indígena" cede terreno a la perplejidad.

Al relatar algunos aspectos del curso sobre "indígenas" recibido en la Allaskuvla, Rita expresaba así esta perplejidad:

Lo que es muy extraño para mí es que ahí... algunas clases fueron sobre el trabajo realizado por Naciones Unidas — una tímida risa - decían que los indígenas... ese concepto... está ligado a los estados nacionales; por ejemplo, ese concepto tal como se usa en el Foro de los Pueblos Indígenas... quienes evalúan quién tiene acceso a la participación en ese Foro están vinculados a los estados nacionales; sin embargo, el hecho es que esos pueblos han vivido ahí, en esa zona, antes de que el estado nacional fuera instituido.

\section{Intersubjetividad agonística}

La revista Pensjonisten publicó en 2003 una entrevista con la anciana maestra de escuela nacida en Guovdageaidnu Edel Hætta Eriksen, titulada Recuerdos de infancia desde la tundra de Finnmark. En ella narraba la siguiente historia:

Tenía escasamente 15 años cuando viajé a Vadsø para asistir a la escuela secundaria. Recuerdo que alguien me preguntó "¿de dónde vienen los samis?” ¡Era una pregunta extraña! Yo respondí: "no lo sé, pero yo vengo de Kautokeino". Después, cuando tuve la oportunidad de leer historia de los samis, llegué a entender mejor. Cuando me hacían esa clase de preguntas, yo respondía: “¿y de dónde vienen los noruegos?" Entonces se producía una respuesta culpable (Hætta Eriksen, 2003: 17).

${ }^{8}$ Asumo aquí como propia la expresión de Britt Kramvig: “categorías flexibles”. Hay en ella una anomalía susceptible de una crítica similar a la que Brubaker y Cooper hicieron de expresiones como "identidades cambiantes" (Brubaker y Cooper, 2000). Sin embargo, la expresión acierta en la diana que me interesa subrayar: la necesidad de indagar en las relaciones étnicas como entornos complejos que son irreductibles a los dispositivos de categorización excluyente. 
Estas ironías verbales encadenadas se basan, una vez más, en el juego con los tiempos: el tiempo originario de un "pueblo", tematizado en la primera pregunta, es irónicamente confrontado con el tiempo presente de Edel, quien, aunque en ningún caso negaría su pertenencia a ese "pueblo", se autodefine de paso como alguien bien diferente de él. La intensidad de la ironía aumenta en la segunda parte del pasaje, una vez situada la cuestión en la "historia de los samis", es decir, en su dimensión específicamente etnopolítica. Ahora ese tiempo originario de un "pueblo", tematizado en la primera pregunta, es confrontado con el presente (duradero) de la ocupación territorial. Edel expresó así una toma de posición temática: no se trata del origen de un pueblo, se trata del presente político en el que tú y yo hemos llegado a vivir. Edel nos permite evocar de nuevo a Fabian, al construir su contemporaneidad con el molesto interlocutor frente a la alocronía que éste le atribuía.

Si la interpretación acerca de la ironía de ser indígena que vengo ofreciendo en este ensayo es adecuada, y si mi lectura de Fabian se aproxima a lo que él quiso decir al escribir Time and the Other (1983); entonces debemos extraer algunas conclusiones de carácter epistemológico sobre los usos analíticos de la palabra "indígena", y, como consecuencia de ello, algunas reflexiones de carácter metodológico. Unas y otras se encuentran ya de forma programática en el libro de Fabian.

Para justificar por qué siento la necesidad de retornar en 2015 a esa obra publicada en 1983 haré una confesión personal. Algunas experiencias recientes con mis intentos de publicación de mis últimos textos basados en mi trabajo de campo en el Ártico, me han llevado a sentir una profunda inseguridad sobre mi interpretación del campo.

Pondré un ejemplo. Un evaluador aderezaba su comentario sobre mi fallida interpretación, indicando que, en las zonas de costa del norte de Noruega, las personas usan la vestimenta reconocida como más típicamente "sami", el gákti, con un sentido análogo a como usan el velo "las mujeres musulmanas en Europa". Naturalmente, poner en relación ambas prácticas de vestimenta pasa por alto que los contextos de uso de esas prendas son infinitamente diversos; también pasa por alto que los entornos de interpretación de ambos tipos de práctica son inconmensurables, salvo que el grado de abstracción ejercido para tal interpretación la convierta en trivial. Pero lo más interesante se encuentra en lo que el comentario afirma positivamente, y en el manifiesto estereotipo orientalista y exotizante que construye. Como esas mujeres "musulmanas" - ¿podría decirse también, en decenas de miles de casos, "europeas"?-, esos "samis" de la costa se expresan a través de un emblema de allí.

A juzgar por los comentarios recibidos, no parece que esos colegas antropólogos estén satisfechos con la idea de que representar una sociedad pretendidamente "indígena" haya de conllevar una afirmación radical del supuesto de que las personas que la habitan viven, aunque de otra forma, en el mundo en el que yo vivo y en el tiempo en el que yo vivo; y, lo que es más importante, se debaten exactamente como yo lo hago, en el esfuerzo agonístico de dotar de alguna inteligibilidad a este mundo, en el que todos vivimos al mismo tiempo. Bajo la atribución de que yo no estoy representando adecuadamente a la "sociedad sami", una noción ya muy comprometida en términos analíticos, parece que algunos de mis colegas de profesión 
siguen creyendo que es condición de la ciencia antropológica objetualizar a la "sociedad" de que se trate, extrayéndola del mundo en el que se genera la interpretación analítica, sacándola de ese mundo y, en definitiva, exotizándola. Algunos de mis colegas confunden, por tanto, la sensibilidad hacia la alteridad, que en mi opinión es condición indispensable de cualquier reflexión antropológica, con la preferencia por el exotismo, que en mi opinión es incompatible con cualquier antropología bien orientada. Puesto que estos colegas se encuentran hoy desarrollando su trabajo en prestigiosas universidades y centros de investigación alrededor del mundo, creo necesario volver sobre Fabian treinta años después.

Como casi siempre, la cuestión epistemológica consiste en un problema de categorización analítica, es decir, en el problema de la validez o la legitimidad de nuestras categorías de análisis: aquí fundamentalmente, "indígena". La ironía de ser indígena se cifra, en este plano epistemológico, en las siguientes palabras de Fernandez y Taylor, escritas al reflexionar sobre el trabajo inevitablemente selectivo que comporta la categorización analítica en nuestra profesión:

La ironía es que pensar exige olvidar. Y eso es irónico porque lo olvidado o lo excluido siempre puede, de un modo u otro, retornar para reafirmarse de forma inadvertida o inintencionada. Muy a menudo, y quizás de una forma más fundamental, la ironía es un cuestionamiento de las categorías establecidas de inclusión y exclusión, y el que ironiza es aquél o aquélla, o ese grupo que ha sido perjudicialmente categorizado, y confinado de ese modo a impugnar a través de la ironía la adecuación de tales categorías (Fernandez y Taylor, 2001: 9).

Empíricamente, la ironía de ser indígena consiste en una experiencia de lo incierto, en particular, una experiencia de la incertidumbre instalada en una categorización de identidad con profundas raíces históricas. Esa experiencia de lo incierto, y la dinámica que mantiene en su relación con las esencializaciones identitarias, es lo que yo quiero representar en mi etnografía: esa experiencia vivida por esos otros que, por su propia textura, inquieta mis propias certezas. Fernandez y Taylor han encontrado, en la aportación de Keith Brown, el término que puede condensar esta actitud: etnografía irónica, una etnografía capaz de establecer como certeza analítica la incertidumbre de la experiencia de la "identidad" en el juego sutil de las identificaciones prácticas (las de todos: los antropólogos y los que no lo son). Ésa es la certeza paradójica que conduce, en palabras de Brown, a una posición "metaestable" del agente (Brown, 1999:16).

Brown sugiere [...] una "etnografía irónica", en sintonía no sólo con el contexto político en el cual los cambios de alianzas de las personas tienen sentido, sino también con el reconocimiento que las personas hacen de las ambigüedades de su pasado y de su presente, y con el humor que derivan de "las certezas de los otros". En otras palabras, como sostiene Brown, los etnógrafos deberían ser conscientes de que las personas que estudian pueden ser Rortyanos productores de ironía: "nunca suficientemente capaces de tomarse a sí mismos en serio, porque siempre son conscientes de que los términos a través de los que se describen a sí mismos están sujetos a cambio" [Brown, 1999:16] (Fernandez y Taylor, 2001:25). 
Estas palabras contienen una hipérbole. Esas personas - no las estudiamos, por cierto, a ellas, estudiamos la acción que ellas generan - sí que son suficientemente capaces de tomarse a sí mismas en serio; yo diría que lo hacen con bastante más seriedad de la que a menudo somos capaces los antropólogos con nuestras categorizaciones. Por eso son capaces de impugnar nuestros discursos, a veces con ironía y a veces literalmente.

En febrero de 2004, el filósofo social Nils Oskal, profesor en la Allaskuvla, me invitó a presentar un texto en un seminario de investigación que coordinaba. El texto, que publiqué en un volumen editado por Luis Díaz con el título "El sujeto en la corriente. Reflexiones sobre el sujeto social en condiciones de globalización" (Díaz de Rada, 2004), se apoyaba en el dualismo entre las nociones de sujeto y agente para relatar los abusos de la ideología de la globalización. El texto que presenté esa tarde ante personas residentes en Guovdageaidnu, docentes en la Escuela Universitaria, contenía una interpretación muy incipiente de algunos materiales empíricos producidos en la localidad. Para dar cuenta de la vida concreta de las personas - decía yo en el texto - no era adecuada ni la imagen de un sujeto sin agencia ni la imagen de una agencia carente de toda forma de sujeción. Según aquella incipiente interpretación mía, esas personas habitaban en un mundo de tradiciones que las sujetaban, pero no tanto como para impedirles transformar relativamente su mundo a través de su acción.

Tanto la presentación de estas ideas en ese seminario como el debate posterior, fueron para mi enfoque analítico de enorme importancia. La crítica que Nils Oskal hizo de mi análisis fue, de hecho, decisiva para la configuración de una reflexión decididamente agencial sobre el concepto de cultura que formalicé años después en Cultura, antropología y otras tonterías (Díaz de Rada, 2010). Al terminar la sesión, Nils me entregó dos folios en los que impugnaba inequívocamente la idea de que esas supuestas tradiciones - cabría añadir aquí, de su mundo "indígena" - sujetasen a nadie de ninguna manera; y subrayaba que la agencia humana es, ante todo, un problema moral que no se puede fundamentar por completo a base de ejemplares empíricos. En concreto, en ese par de folios me recordaba la vieja reflexión de Kant, según la cual, (cito el texto de Nils Oskal): "Las acciones humanas tienen inscritas sus propias razones (o motivos), y por tanto no pueden explicarse totalmente con el recurso a cadenas causales anteriores". Dicho lo cual, afirmaba taxativamente: "el ser humano tiene constantemente la posibilidad de decir no al mundo"'.

La lección metodológica que extraigo de este intercambio con Nils, y con muchos otros en Guovdageaidnu a lo largo de mi trabajo de campo, tiene que ver con una reformulación del problema de la intersubjetividad. En La lógica de la investigación etnográfica escribí con Honorio Velasco la idea de que en etnografía reformulamos la objetividad en términos de intersubjetividad (Velasco y Díaz de Rada,

${ }^{9}$ Esta expresión, que resume a la perfección lo que se conoce como idealismo kantiano, fue motivada por mi insistencia en las sujeciones de la tradición. Ante esa insistencia mía, Nils no tenía otro remedio que ser taxativo. Tal idealismo independiente de todo contexto de práctica no es en modo alguno atribuible al propio Nils Oskal, tal y como lo ha venido mostrando en sus propios textos (por ejemplo, Oskal, 1999). 
1997). Se entiende que la prioridad de tal relación de conceptos recae sobre la idea de objetividad, o, al menos, sobre la necesidad analítica de configurar un objeto. Naturalmente, negar esta necesidad a cualquier forma de conocimiento que se pretende debatible sería una falacia. Sin embargo, en la medida en que mi aproximación al campo parte de la premisa de la radical contemporaneidad entre el investigador y las personas cuya acción todos toman por objeto en concretas situaciones comunicativas, empieza a cobrar forma la idea de una intersubjetividad en la que todos, tanto el investigador como las personas del campo, intentan dar forma a la experiencia de lo incierto. Pues, como indicó Fabian,

Decir que la distancia reflexiva es necesaria para alcanzar la objetivación no significa que el Otro, en virtud de haber sido localizado en nuestro pasado, se convierta en algo parecido a una cosa, o en una entidad abstracta y general (Fabian, 1983:93).

El objeto de mi investigación es, precisamente, ese proceso incierto de conformación (Carrithers, 2009), en el que se produce la cultura como discurso de acción (Díaz de Rada, 2010: 181ss.). Ese objeto no sólo es mío, también es su objeto. La noción de intersubjetividad agonística que propongo aquí se da la mano con las nociones de "reflexividad colectiva" de Johannes Fabian (1983:92) y de "antropología doblemente reflexiva" de Gunther Dietz (2011); y en gran medida puede ser reducida a ellas. El atributo "agonístico" sólo busca hacer énfasis en el carácter puramente exploratorio e impredecible de una búsqueda de certezas relativas entre personas que, tal vez, saben de antemano que no poseen por derecho propio el recurso a la verdad.

Hace unas semanas escribí a una amiga de Guovdageaidnu un mail en el que le pedía un favor. Tras el enésimo rechazo de uno de mis textos en una revista, y sumido en una profunda crisis de fe sobre mi propio trabajo analítico, le solicité que lo leyera, no fuera a ser cierto que, efectivamente, mi representación de su mundo social estuviera completamente desorientada. No le pedía tanto que validase mi interpretación lógico-empírica, cosa que naturalmente a nadie debe sugerirse, como que me indicase si, a su juicio, ese texto reflejaba de forma más o menos aproximada la vida contemporánea de la gente en Guovdageaidnu. Después de leerlo, y tras algunos intercambios rápidos, me envió el siguiente mensaje:

El asunto que tratas es importante para que la gente llegue a entender que las sociedades indígenas viven "en el mismo mundo" que los demás. Has trabajado [...] para argumentar que esta sociedad no se ha "detenido". Fácilmente puede verse que las personas creen que la sociedad sami no es tan moderna como otras sociedades. Y eso se toma frecuentemente como un argumento contra los samis: no se puede ser ya "indígena" si no te has quedado detenido en la sociedad de 1500. Si tienes coche, ordenador, televisión, y un retrete dentro de tu casa (y no fuera de ella), entonces no puedes ser "indígena". Esto muestra bien el contenido que se encierra en ese término; lo que debería conducirnos a buscar otros. 


\section{Referencias bibliográficas}

\section{ARES, Berta.}

1990 "Estudio preliminar: Tomás López Medel y su defensa del Nuevo Mundo", en Tomás López Medel, ca. 1570, De los tres elementos. Tratado sobre la naturaleza y el hombre del Nuevo Mundo. Madrid: Alianza, VII-LXXVII.

BAUMANN, Gerd; GINGRICH, Andre (Eds.).

2004 Grammars of Identity / Alterity. A Structural Approach. Nueva York: Berghahn.

BLOM-DAHL, Christen A.

1991 Norsk-Spansk blå ordbok. Oslo: Kunnskapsforlaget.

BROWN, Keith S.

1999 "Marginal Narratives and Shifty Natives: Ironic Ethnography as Antinationalist Discourse". Anthropology Today, 15 (1):13-16.

BRUBAKER, Rogers; COOPER, Frederick.

2000 "Beyond identity". Theory and Society, 29: 1-47.

CARRITHERS, Michael (Ed.).

2009 Culture, Rhetoric, and The Vicissitudes of Life, Nueva York: Berghahn.

CLIFFORD, James.

1986 “On Ethnographic Allegory”, en James Clifford y George E. Marcus (Eds.), Writing Cultures: The Poetics and Politics of Ethnography, Berkeley: University of California Press, 121-156.

DÍAZ DE RADA, Ángel.

2004 "El sujeto en la corriente. Reflexiones sobre el sujeto social en condiciones de globalización", en Luis Díaz G. Viana (Coord.), El nuevo orden del caos: consecuencias socioculturales de la globalización. Madrid: CSIC, 77-102.

2008a “¿Dónde está la frontera? Prejuicios de campo y problemas de escala en la estructuración étnica en Sápmi”, Revista de Dialectología y Tradiciones populares, LXIII, $1: 187-235$.

2008b “Qué obstáculos encuentra la etnografía cuando se practica en instituciones escolares?”, en María Isabel Jociles y Adela Franzé (Eds.), ¿Es la escuela el problema? Perspectivas socio-antropológicas de etnografía y educación. Madrid. Trotta. Pp. 24-48.

2010 Cultura, antropología y otras tonterías. Madrid: Trotta.

DIETZ, Gunther.

2011 "Hacia una etnografía doblemente reflexiva: una propuesta desde la antropología de la interculturalidad". AIBR. Revista de Antropología Iberoamericana, 6, 1:3-26.

FABIAN, Johannes.

1983 Time and the Other. How Anthropology Makes its Object. Nueva York: Columbia University Press.

FERNÁNDEZ DE NAVARRETE, Martín.

1999 Viajes de Cristóbal Colón. Madrid: Espasa Calpe. 
FERNANDEZ, James W.

2006 [1982] "La oscuridad al fondo de la escalera. Lo incoado en la investigación simbólica y algunas estrategias para abordarlo", en En el dominio del tropo: Imaginación figurativa y vida social en España. Madrid: UNED, 285-314.

FERNANDEZ, James W.; TAYLOR HUBER, Mary.

2001 "Introduction: The Anthropology of Irony", en James W. Fernandez y Mary Taylor Huber (Eds.), Irony in Action. Anthropology, Practice, and the Moral Imagination. Chicago: The University of Chicago Press, pp. 1-37.

HÆTTA ERIKSEN, Edel.

2003 "Barndomsminner fra Finnmarksvidda", Pensjonisten, 6.

JONASSEN, Øyvind.

1959 "Sosiale og hygieniske forhold i flyttsamenes basisområde", en Kirke- og Undervisningsdepartementet, Instilling fra Komiteen til å utrede samespørsmål. Mysen: Indre Smaaleneness Trykkeri, pp. 83-88.

KÅVEN, Brita, et al.

1995 Sámi-dáru sátnegirji, Kárašjohka: Davvi Girji.

KERBRAT-ORECCHIONI, Catherine.

1980 "L'ironie comme trope". Poétique. Revue de théorie et d'analyse littéraires, 41:108-127.

KIRKE- OG UNDERVISNINGSDEPARTEMENTET.

1959 Instilling fra Komiteen til å utrede samespørsmål. Mysen: Indre Smaaleneness Trykkeri.

KOCKELMAN, Paul.

2007 "Agency: The Relation between Meaning, Power, and Knowledge". Current Anthropology, 48(3):375-401.

KRAMVIG, Britt.

1999 "I kategorienes vold", en Harald Eidheim (Ed.), Samer og nordmenn, Oslo: Cappelen Akademiskforlag, pp. 117-139.

2005 "Fleksible kategorier, fleksible liv", Norsk Antropologisk Tidskrift, 16, 2-3:97-108.

LÓPEZ MEDEL, Tomás.

ca. 1570 De los tres elementos. Tratado sobre la naturaleza y el hombre del Nuevo Mundo. Madrid: Alianza. (Edición de 1990 a cargo de Berta Ares).

LOVDATA.NO.

1814-2014 https:/lovdata.no/dokument/NL/lov/1814-05-17?q=grunnlov, Kongeriket Norges Grunnlov [Constitución del Reino de Noruega]. Última Consulta: 5 de noviembre de 2014.

MARTIN, Robert.

1992 "Irony and The Universe of Belief", Lingua, 87:77-90. 
MINDE, Henry.

1995 "The International Movement of Indigenous Peoples: An Historical Perspective", en Terje Brantenberg et al. (Eds.), Becoming Visible. Indigenous Politics and Indigenous Self-Government, Tromsø: Senter for Samiske Studies Skriftserie, 2:9-25.

NOU (Norges Offentilge Utredninger).

1984 Om samenes rettstilling, NOU, 18. Oslo: Universitetforlaget.

OSKAL, Nils.

1999 "The Moral Foundation for The Disqualification of Aboriginal's Peoples Proprietary Rights to Land and Political Sovereignity", en Tom G. Svensson (Ed.), On Costumary Law and The Saami Rights Process in Norway, Tromsø: Senter for Samiske Studier, Skriftserie, 8:99-113.

RICOEUR, Paul.

1990 Soi-même comme un autre. Paris: Seuil.

SPERBER, Dan; WILSON, Deirdre.

1981 "Irony and The Use-Mention Distinction", en Peter Cole (Ed.), Radical Pragmatics. Nueva York: Academic Press, pp. 295-318.

TAYLOR HUBER, Mary.

2001 "Irony and Paradox in the 'Contact Zone': Missionary Discourse in Northern Papua New Guinea", en James W. Fernandez y Mary Taylor Huber (Eds.), Irony in Action. Anthropology, Practice, and the Moral Imagination. Chicago: The University of Chicago Press, pp. 188-208.

VELASCO, Honorio; DÍAZ DE RADA, Ángel.

1997 La lógica de la investigación etnográfica. Un modelo de trabajo para etnógrafos de la escuela. Madrid: Trotta.

VESPUCCI, Amerigo.

1502 “Carta de 1502”, en Cartas de viaje, Madrid: Alianza, pp. 74-80. (Edición de 1986 a cargo de Luciano Formisano).

WILSON, Deirdre; SPERBER, Dan.

1992 “On Verbal Irony”, Lingua, 87:53-76. 